TTTLE: PHIDOSOPHY OF A COMPUTER-AUTOMAZED COUNTING SYSTEM

AUTHOR(S): Deanis G. Perry and Gregg C. Glesler

SUBMITTED TO: Topical Conference on Computerized Data-Acquisition Syctems in Particle and Nuclear Physics, Santa Fe, New Mexico, May 14-17, 1979

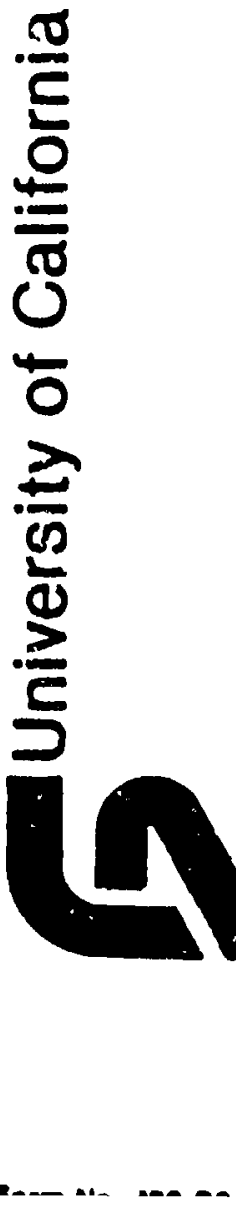

Gy ecepptenes of this aricis, the publisher recoenizes thet the U.S. Gowmment netins e nonexetusiv, royalty-fres llame to publish or reproduce the oublished form of this contribu. tion, or to allow othen to do so, for U.S. Government purposen.

The Los Alames Scientifie Leboretery requests thet the pub. lieher identhy this article a mork pertormed under the sus. plese of the U.S. Department of Energy. 


\section{PHILOSOPHY OF A COMPUTER-AUTOMATED COUNTING SYSTEM -}

Dennis G. Perry and Gregg C. Giesler*

\section{Abstract}

The LAMPF Nuclear Chemistry computer system is designed to provide both real-time control of data acquisition and facilities for data processing for a large variety of users. It is a PDP-11/34 connected to a parallel CAMAC branch highway as well as a large variety of peripherals. The philosophy for the design of this system will be discussed, and will cover such points as use of the computer for control only versus direct data acquisition by the computer, why a CAMAC system was chosen, and the advantages and disadvantages of this system. Also to be discussed will be future expansion of the system and what might be done differently if the system were redesigned.

\section{The Nuclear Chemistry Laboratory}

The Los Alamos Clinton P. Anderson Meson Physics Facility (LAMPF) is a medium energy, 800-

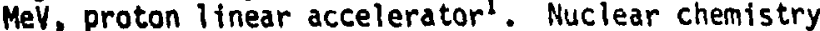
experiments may be conducted at LAMPF using either the direct proton beam or any of the secondary beams of muons, pions, or neutrons. The targets irradiated in any of these beams may be transported to the Nuclear Chemistry Laboratory (NCL) manualiy, or via a pneumatic transfer systein, where they are analyzed.

The NCL consists of four chemistry laboratorles, five counting rooms, and of $i c *$ space for staff and visiting scientists (see figure 1). The basement: area can also be used for counting equipment. The types of equipment used for data aquisition include $\alpha$ and $\beta$ profortional counters, lowbackground $\beta$ proportional counters, a spectrometers, posttron annihilation counters, $B-\gamma$ colncidence counters, $\mathrm{NaI}$ (TI) and $\mathrm{Ge}(\mathrm{L}$ i) $\gamma$-ray spectrometers, and a large $\mathrm{Ge}(\mathrm{L} i)$ anti-Compton spectrometer.

These various counters are connected to a large number of scaler-timers and multichannel analyzers (MCAs) to collect the data.

* Los Alamos Scientific Laboratory Los Alamus, NM 87544

\section{The NCL Data Acquisition System}

The NCL Data ACquisition System (DAS) is a Digital POP-11/34 (Figure 2) with a floating point processor, 128k words of memory, two magnetic tapes, two DEC tapes, three removable disk cartridge drives of $1.2 \mathrm{M}$ words each, a paper tape reader punch, one removable disk pack drive of $20 \mathrm{M}$ words, a $5021 \mathrm{pm}$ printer/plotter, two storage display consoles which are also connected to the printer/plotter for hard

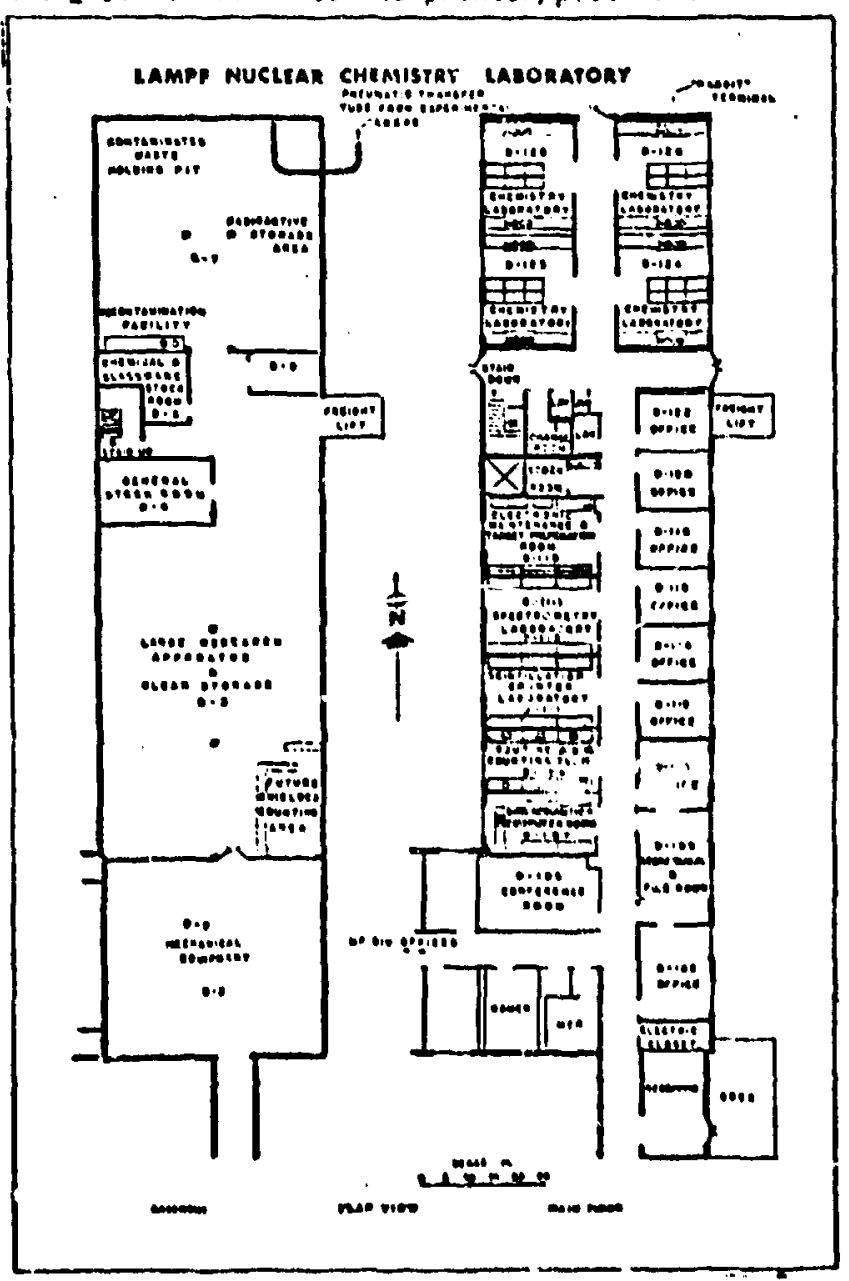

Figure 1. A plan view of the Nuclear Chemlstry Laboratory at LANPF. 
copy outpl: three CRT control conscles, and a DECwriter system control console. The systen also has a special purpose computer, a Microprogrammed Branch Driver (MBD $)^{2}$, to interface the PDP. 11/34 to the $\mathrm{CA}: A C$ Branch Highway.

The CAMAC Branch Highway' contains all the connections to the various counting systems. The scaler-timers are connected in paralle? with the scaier-timers on the nun-spectrometer counters and the MCA inter'sces are connectr's to a variety of multichannel analyzers to provide direct computer readout and contrcl. The dual-parameter data acquisition systeii is a special design using a DEC LSI 11 computer as a base and can conmunicate with the PDP-11/34 through the branch highway. In addition to thes data acquisition units, the CAMAC system also has an interface to the Julian clock providing time-of year information throughout the counting rooms and chemistry lato tories. Also interfaced to thi: computer through CAMAC is an IBH, C?? or U29 keypunch which operates as an sutput device.

Trie computer is used to control the $c^{\cdots} \cdot$ nting rooms through th's CAMAC Branch Highway and to collect data from nuclear chemistry experiments. These experiments are all off-line experiments of counting induced radioactivity. The POP-11/34 is also used for data analys is al though its main function is data acquisition and control.

\section{Experimenter Interaction}

The basic operation of the POP-11/34 is controlied through Digital's RSX-110 operating system, a multi-user, multiprogrammed system. The dataacquisition system consists primarily of specia? purpose software with some use of a collection of programs called "Q", a general data acquisition system developed at LAMPF for use in the on-line experirental nuclear physics program4.

The experimenter inieracts with the control computer via a CRT console and a CAMAC crate in each counting room (Figure 3). Throigh the CRT console, the experimenter can initialize the data-acquisition programs to be used and can enter additional information about the samples being counted. They are al-u used to monitor progress of the experiments.

In addition to data acquisition modules, each C.MAC crate contains an Event Trigger module ${ }^{5}$. One function of this module is experimenter-generated LAMs. These LAMs can be used by data-acquisition programs to interactively change operating parameters.

\section{Philosophy of Design}

In 1973 when the design was begun, it was known what types of counting equipment were to be supported, since this counting system is a small version of one already existing in the nuclear

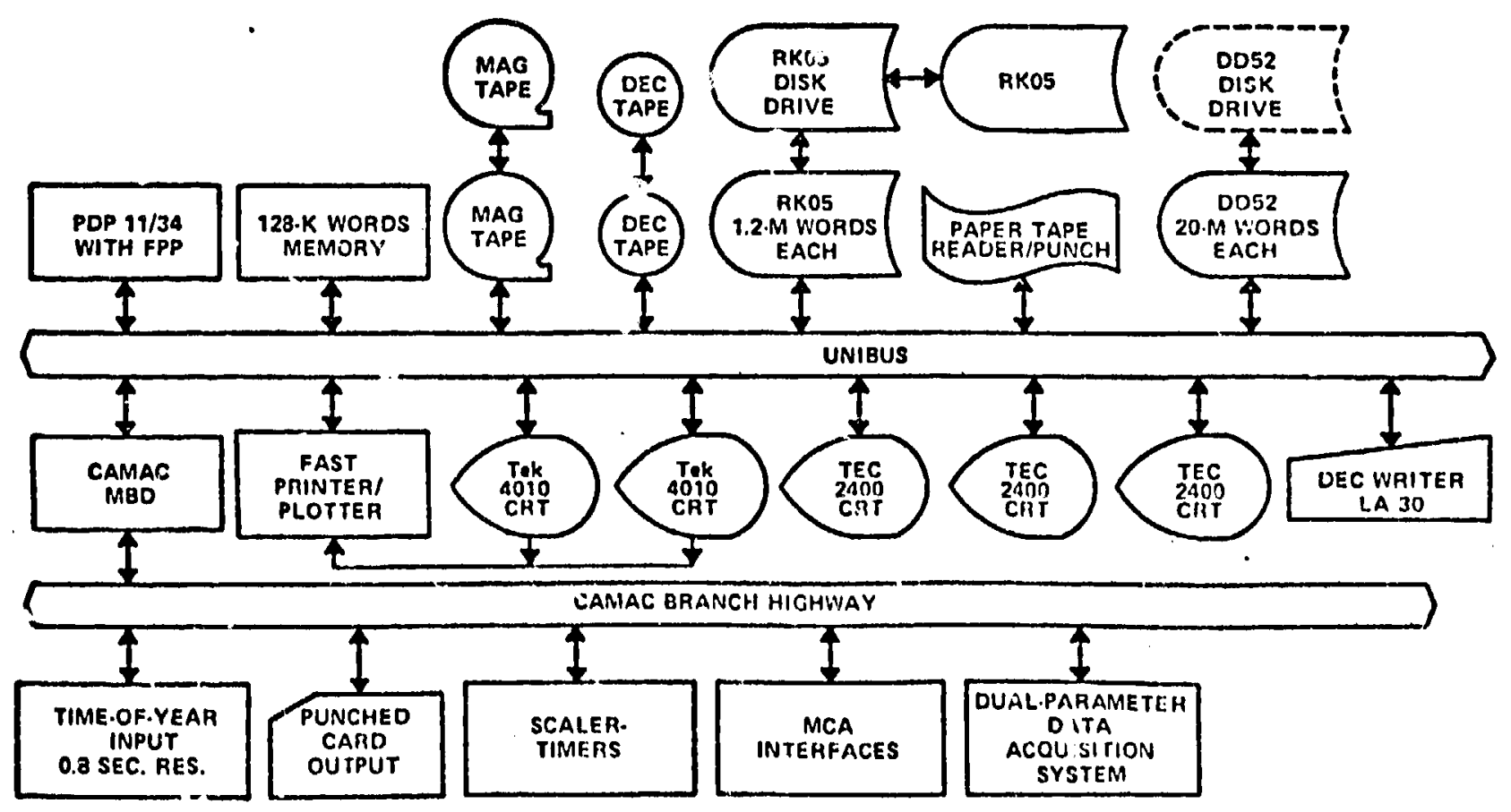

Figure 2. The NCL Data Aquisition Computer System. 


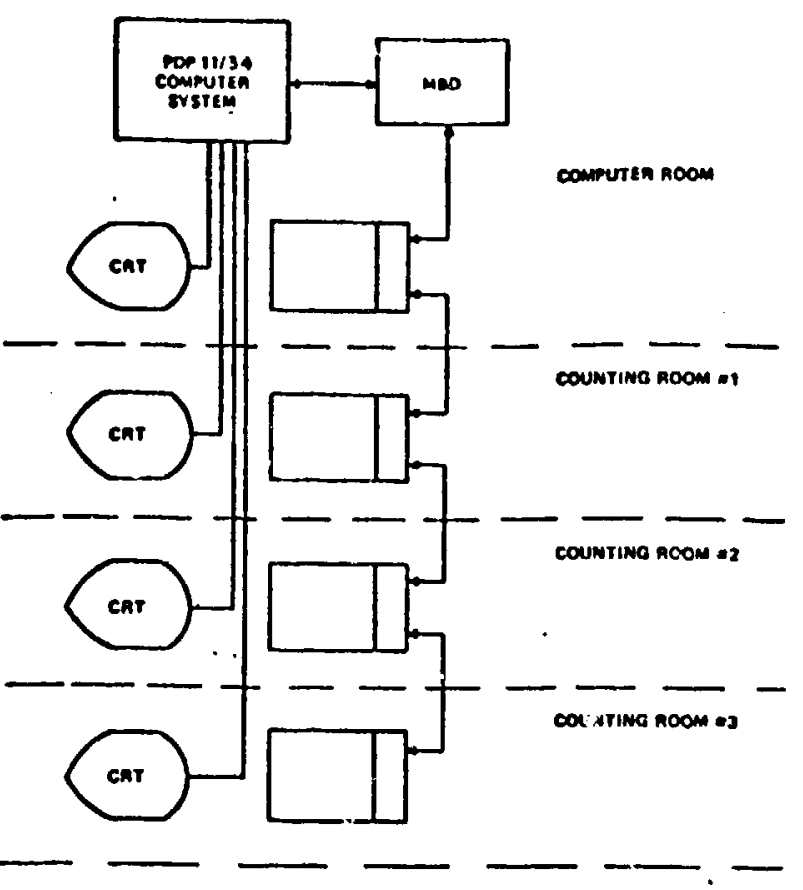

Figure 3. The CAMAC Branch Highway of the NCL DAS The CRT in each counting room is used to communicate with the computer.

chemistry group. Many scalers and timers are needed for the $\alpha$ and $B$ proportional counters, Lile $B-Y$ coincidence counter, and the positron annihilation counters. Also, a number of MCAs are needed for the various spectrometers.

One way to provide these functions is by direct connection of the signals to be scaled and the analog-to-digital converters ( $A D C$ s) for the spectrometers to Unibus interfaces. The computer wolld then have to respond to each event from each counter and $A D C$ as well as keep an elapsed time ciock for each input. This obviously would easily overload the computer and therefore not be feasab e.

By froviding scalers, timers and multichannel analyzers as units separate from the computer, most of the direct data acquisition load would be taken off the main computer. The computer would only need to set the various counters to the desired count length and then read out the data when the coun iers were done counting. The internal bookkeeping wo'lld be greatly simplified and more counters could to supported.

\section{Selection of CAMAC}

With the decision made to interface external collection units to the computer, the next step was to find the best way to do it. Several manufacturers of nuclear counting equipment had pro- prietory 'usses to connect their modules together ard to a printer or teletype. These bissses are rather slow and have linited capatili iny for computer contact of the counting modules.

Connecting these modules directly to the computer bus itself is another possibility. However, due to the large number of modules involved and the fact that they are in four counting laboratories several Unibus repeaters would be needed. Also, a large number of non-counting peripherals are already heavily loading the bus. Therefore, this option is unuseable.

The only apparent remaining choice is the CAMAC Branch Highway. The units used in a CAMAC system are modular and therefore very portable, similar to existing NIM units. Since there are many standard, off-the-shelf units, they provide great flexability in how to configure and reconfigure a systen. This sytem is also easily expandable.

With these advantages come several disadvantages. Although many of the units we needed were sta.ndard NIli designs, no equivalent CAMAC modules existed As a result, most of our CAMAC modules, all those shown in Figure 2, were custom designed.

Associated with this are the problems of having them repaired since they were the only ones of their $k$ ind in tive world. Repairs are performed by a laboratory in-house electronics ma intenance group with some consultation with the manufacturer. Since other people have the similar needs for their counting systems, some of these CAilAC modules are now available conmercially, and thus more support and documentation is available when problems occur.

An obvious second problem is software. Since the CAMAC modules are custom designed, the software must be also be custom designed. A large amount of effort by LAMPF prograrmers has gone into the data acquisition package called "Q" 5 . This set of programs provides the user a very powerful too? with which to control his CAMAC system. Its primary disadvantage is that it is a single user system. Since we have to provide counting facilities or several users at a time, we must use a subset of "Q". This subset is slow, one CAMAC conmand at a time, and is not interrupt driveir. As a result, reading out a multichannel analyzer takes a few minutes instead of a few secords.

\section{Peripherals}

The original proposal for this data acquisition system included a PDP. $11 / 40$ with $83 \mathrm{k}$ words of memory, one LA30 Console, two Tektronix 4010 graphic terminals, one RKO5 disk drive, two DECtape drives, a paper tape reader/punch and twio IBM 729 7-track magnetic tape drives. This configuration was based on one proposed for LAMPF data 
acquisition systems ${ }^{6}$. Very rapidiv the need for the three CRT cunsoles and the two additional RKOS disk drives appeared and they were purchased. The OEC tapes and paper tape system were purchased since they were the then available system software distribution media and also the only means for intercomputer sof tware distribution

As use of this system increased, the need for a printer/plotter and the full 128k-words of memory developed. With these itcms added to the system, the use and useability of the system further increased. Now two of the RK05s were needed just for operating system and locally written data acquisition programs. This left only one disk drive to be shared by all user for their programs and data. Also, much of the data came from off-line MCAs via 7-track 556 bpi magnetic tape. With the low data density on the tapes and the unreliability of the old tape drives, it was apparent that changes had to be made. As a result, the magnetic tape drives on the DAS and the oft-line MCA tape drives are being converted to 9-track. Also a 20M-word disk drive was purchased.

As a result, this system has a large variety of Deripherals, perhaps too many for good sysiem reliability. The DEC tapes currently are rarely used. For several years, the paper tape hardware was rarely used. However, because of the PDP-11/03 connection through CAMAC, it is again being used for high speed reading of diagnostics for the POP-11/03. With the addition of the large disk sytem to the DAS, the use of the RK05s, has greatly decreased, but they are still used for data storage for individual experimenters and program and data transfers between computers. So, although use of many of the peripherals has decreased, they are still occasionally needed.

During this perioc, we also had problems due to the inability to add a floating point processur to the PDP-11/40. In particular, we could not easily do double precisicn (32-bit) integer operations, and floating point operations were done in software which is considerably slower than hardware. Since another group within the laboratory was ir.ter p ted in trading PDP-11/345 to get POP-11/40s, we caded and immediately added a flaating point processor to the new central processor.

\section{Future Expansions}

In each counting room is a CAMAC crate and an alphanumeric CRT. This works out fine for controlling the counting. However, these terminals have no nraphic capabilities. Therefore, it is planned to add a graphic terminal to each of the counting rooms in addition to the equipment aiready there. This will allow the experimenter to analyze $h$ is data as soon as it is read out rather than wait until after the experiment is over or run back and forth between the graphic terminals in the computer room and the rooms where his counting is being done
Since several of our MCAs are very old, they have no computer control capability. They are being replaced with modern, microprocessor based MCAs that can b. completely controlled by the central computar. This will provide greater versatility for the experimenters.

With all this new hardware, the software will also have to be improved. "Q" will have to be mudified to provide at least a pseudo multiuser capability. This increase in the speed of reading o.1t the MCAs is rapidly becoming necessary.

\section{What Would We Do If...}

All this leads to what would we do differently if one could start over. This question is difficult to answer because of the rapid developent of electronics in the six years since this system was initially proposed. Time has shown that many of the decisions made were correct. The biggest problem was the lack of sufficient manpower when the system was first installed. As a result, much of the current effort is catching up with users needs and desires and getting the best utilization of the various counters.

A second area of improvement would be the POP 11/03 based, dual-parameter data acquisition system ${ }^{7}$. It uses a spacially designed interface to provide control signals and route the $A D C$ data either to a PDP-11/03 or oirectly though CAMAC to the central computer. Due to the complexity of the unit and the difficulty in developing a system that works both with the strobed CAMAC system and the interrupt driven PDP-11/03, this system could be better implemented with CAMAC ADCs and a conputer in an auxiliary crate controller. Both the hardivare and sof tware would be much simpier.

It should be mentioned tinat such hardivare was not commerically available when $11 / 03$ system was designed and built. Our experience has shown that unless adequate support is available in-house one should try to meet one's requirements through the use of commerical equipment when at all possible.

\section{Summary}

The LAMPF Nuclear Chemistry computer system is designed to provide both real-time control of data acquisition and data andys is for a large variety of users. The system is a POP-i1/3! connected to a parailel CAitAC Branch Highway as viell as a variety of peripherials. The CAMAC system was chosen for the data acquisition because of its standardization, flexability, modularity and its comilerical availability. The CAPIAC system provides a means of connectinc a lare variety of units to a central coinputer without loading down the computer and its bus. As this system has evolved both in scftware and hardware, more experimenters have made use of $i:$. In turn, this has required adding 
more sof tware and hardware. Eventually, the data acquisition will push the data analysis to larger and faster computers and may even require another replacement of the central processor with a more powerful and faster model.

\section{References}

1. L. Rosen, "The Clinton P. Anderson Meson Physics Factlity (LAMPF)", Pro. Nat. Acad. Sc1. USA, 70. No. 2, 603-610. Feluruary 1973.

2. L. R. 8iswell and R. E. Rajala, "Design and Operation of a Microprogranmed Branch Ortver for a PDP-11 Computer". LA-5144, Los Alamos Scientific Laboratory, 1-28, May 1973.

3. See for example "CAMAC" which consists of IEEE Std 583-1975. IEEE Std 595-1976, IEEE Std 596-1976, and IEEE Std 06437.

4. M. Kellog, et al, "Introductory to Q" A-7001$M_{1}$ Los Alamos Scientific Laboratory, ; - 26 , June 1978; also, D.G. Perry, "The Q Systern: An Experiment in Software Standardization for Data Acquisition", elsewhere in this proceedings.

5. J. D. Nickell, "Technical Description LAMPF Event Trigger Module", MP-1-3315, Los A1 amos Scientific Laboratory, 1-8, June 1975.

6. H. L. Anderson, et al, "LAMPF Data Acqu isition System", LA-4504-MS, Los Alanos Scientiftc Labnratory, 1-21, August 1970; R. F. Thomas, et al. "Coinputing in Support of Experiments at LAMPF". LA-6543-HS, Los Alamos Scientific Laboratory, 1-24, October 1978.

7. G. C. Giesler and D. G. Perry, "A PDP-11/03 Based Dual-Parameter Data Acquisition System". Proc. Digital Equipment Computer Users Soctety, 4. No. 2, 591-595, December 1977. 